\title{
Food Sources and Preferences of College Students
}

\author{
Deric Hardy, Deric, MS \\ Ejimakor Godfrey, PhD \\ Dr. Obed Quaicoe, PhD
}

North Carolina A\&T State University, NC U.S.A.

Doi: 10.19044/esj.2017.c1p7 URL:http://dx.doi.org/10.19044/esj.2017.c1p7

\begin{abstract}
Young adults, especially college students, in the United States (U.S.) have to make independent decisions on where to buy food and the attributes of the food to buy. For some, the decision is one of their first undertakings since leaving home and could be foundational relative to their food choices, with its attendant health implications, later in life. We used a data from a survey to ascertain the frequency with which some U.S. college students shop at different types of food vendors such as grocery stores, supermarkets, fast food restaurants and full-service restaurants. We also asked about the food attributes that were important to students. Our results indicate that supermarkets were the primary sources of food at home for the students while fast food restaurants were the dominant sources of food away from home. Taste, followed by price, were the most important food attributes for students. Most students indicated a willingness to pay more for local food and food produced on small farms. Food vendors that could provide food that tastes good at lower prices are likely to have a competitive edge in attracting college students as patrons. The interest of students in local foods suggests that the current local foods movement may not be a fad, but could be sustained for a longer period.
\end{abstract}

Keywords: Food, preference, price, taste, restaurant

\section{Introduction}

Food intake is an important subject that has enormous health and economic implications. Studies have shown that most college students often have poor eating habits (Brevard and Ricketts, 1996; Driskell, Kim, and Goebel, 2005; Racette, Deusinger, Strube, Highstein, and Deusinger, 2005). According to Grace (1997), college life often deteriorates dietary habits among students. This could potentially add to weight problems especially during the first year of college (Anderson et al., 2003) and possibly continue 
during later years of life (Centers for Disease Control, 1997; Driskell et al., 2005; Racette et al., 2005). Therefore, studies related to food choices and consumption behaviors among millennials need to be taken seriously since it has several long-term consequences for the individual in terms of health and longevity and to society with regard to health costs. Where and why younger people buy given food items are useful information for developing effective food marketing and nutritional education programs.

The existing literature on food choices cite taste, cost, nutrition, convenience, pleasure, and weight control as the key determinants of food selection and consumption (Sporny and Contento, 1995; Nguyen, Otis and Potvin, 1996; and Glanz et al. 1998). However, some studies show that the cost of food and convenience are the highest determining factors in the choice of food among millennials or young folks compared to older persons (Glanz et al., 1998). Also among the cohort of millennials, cost of food and convenience are found to be important to nonwhites, especially blacks, compared to whites (Glanz et al., 1998). This implies that though some young consumers may have concerns about certain kinds of food produced conventionally, their preference for alternatives is usually conditional, and quite often determined by food prices. Besides cost, Bisonette and Contento (2001) also argue that young people are more likely to admit that they intend to buy organically produced food. Gender differences among millennials also exist when it comes to food preferences. Racette et al. (2005) reveal that female college students tend to eat more fatty foods than male counterparts, although their fruit and vegetable consumption tend to remain similar.

Birch (1999) has shown that people often establish their eating habits while they are relatively young but little research has been done focusing on the food selection behaviors of young adults or millennials (Betts et al., 1995). The intent of this study is to identify and evaluate the food preferences of millennials, especially college students, in order to gain better insights in their consumption behaviors. This is very important because young consumers are likely to take their eating habits into their older age. Although many food preferences are established at an early stage in life, people still make more independent decisions about their food intake as they move through adolescence (Deshpande, Basil and Basil, 2009). For the very young, many food choices are constrained by the decisions of parents and pre-college systems (Nicklas et al., 2001). Thus, an essential time of life for food choice is when people step out independently for the first time and begin to make their own decisions about food. For many people, this is the transition to college or university life. Transitioning to college or university is a critical period for young adults who are facing their first opportunity to make their own food decisions (Baker, 1991; Marquis, 2005) and could have a negative impact on students' eating behaviors (Marquis, 2005; Rappoport, 2003). 
Therefore, a clear understanding of young people's decision about food choice and consumption will help to promote desirable behaviors (Glanz, Lewis and Rimer, 1997; and Glanz and Eriksen, 1993).

\section{Methods}

We collected data for this study through a survey which was administered to a convenience sample of 120 undergraduate students at North Carolina Agricultural and Technical State University in Greensboro, North Carolina, in the Spring of 2016. The students were majors in animal science, agribusiness, agricultural education, environmental science and economics. The data was collected by using a survey instrument entitled 'Food from Our Changing World: What Do You Think? (Wimberley, Vander Mey, Wells and Ejimakor, 2003). The students were requested to respond to categories of question/statements on where and how often they bought their food, the importance of food attributes and willingness to pay more for food based on how and where it was produced. Where students bought their food was further sub-categorized as either food at home (FAH), which included raw food from supermarkets, grocery stores and convenience stores, and food away from home (FAFH) which included prepared food from fast food restaurants, cafeterias and full-service restaurants, and ready-to-eat food items. Students were asked to indicate how often they bought food from the various FAH and FAFH sources. The possible responses to this category of questions were: daily, weekly, monthly, seldom or never. On the category for food attributes, students were requested to rate the importance of food labels, taste, and price. The possible responses were of: no, little, some or great, importance. The third category of questions asked students to indicate whether they will be willing to pay more for food based on where and how the food was produced, and how it was processed, which included food produced locally, organically, on small farms, and grown and processed in safe conditions. The possible responses were strongly, agree, undecided, disagree and strongly disagree. The responses were coded, tabulated and used to generate graphs.

\section{Results}

\section{Food at Home}

Supermarkets were the predominant source of FAH for students. Almost 94 percent of the respondents purchase their groceries from a supermarket on a daily (1.6\%), weekly (51.6\%) and monthly (40.6\%) basis (Figure 1). Convenience stores were the second most important source of food at home with $61 \%$ of the respondents indicating that they patronized the outfits on a, daily (14.1\%), weekly (34.4\%) or monthly (12.5\%) basis. The frequency of daily visits to convenience stores was higher than those for supermarkets 
and grocery stores. Over $50 \%$ of the respondents seldom or never shopped at a local grocery store.

\section{Food Away from Home}

Fast food restaurants were found to be the primary source of food away from home (FAFH) for the respondents. Twenty-five percent of the respondents bought FAFH from fast food restaurants on a daily basis while over half $(51.6 \%)$ and $12.5 \%$ did so on a weekly and monthly basis, respectively (Figure 2). Cafeterias and full service restaurants represented the second most important source of food away from home. Over $33.3 \%$ of the respondents patronized cafeterias and restaurants weekly and $30.2 \%$ did so monthly. The least likely source of food away from home were ready-to-eat food items from grocery stores. Over 30\% of the respondents reported that they seldom or never bought ready-to-eat food items from grocery stores, which is about three times the rate for fast food restaurants and almost twice the rate reported for cafeterias and full-service restaurants.

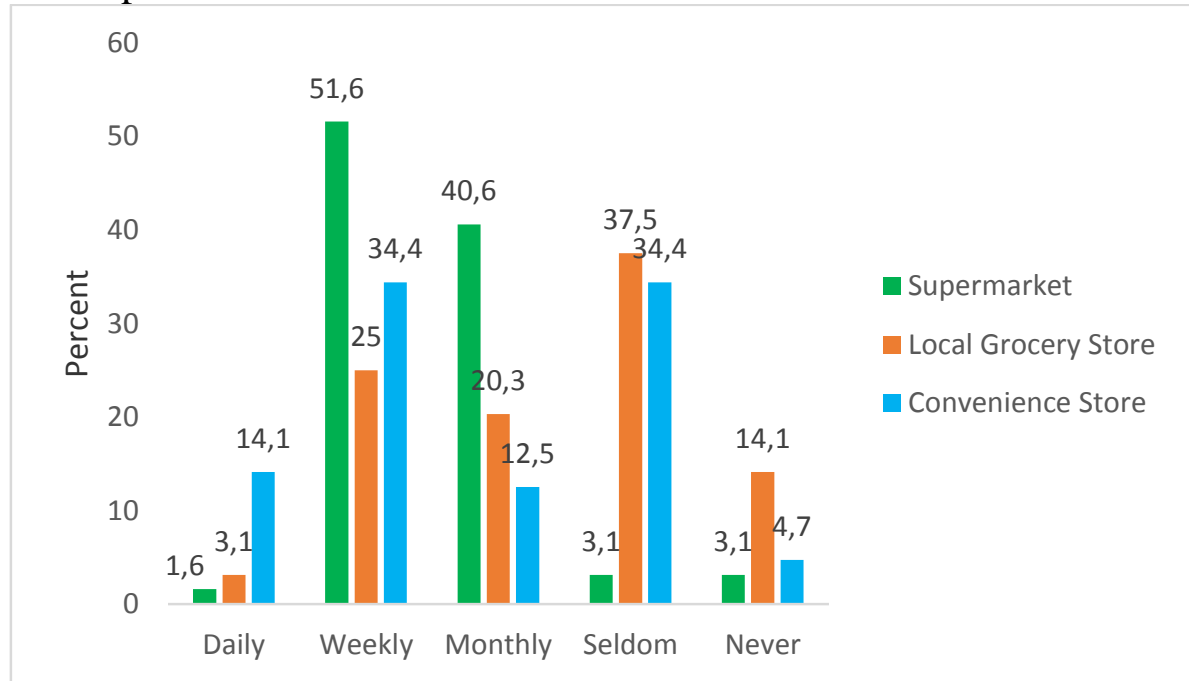

Figure 1: Frequency of Shopping for Food at Home by Type of Store 


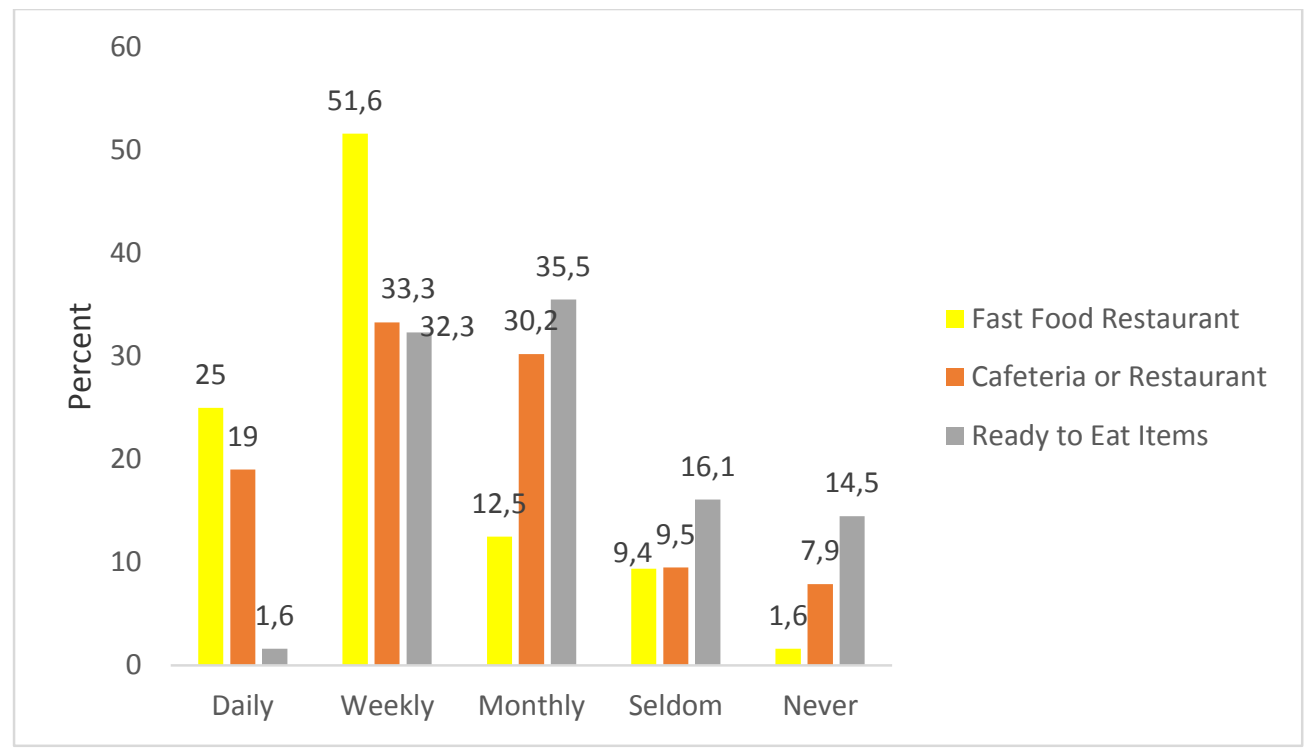

Figure 2: Frequency of Shopping for Food Away From Home by Type of Restaurant Store Types

\section{Importance of Food Attributes}

Taste was found to be the most important food attribute. Over $81 \%$ of the respondents indicated that food taste was of great importance while an additional $12.5 \%$ indicated that taste was of some importance (Figure 3). The second most important food attribute was the price which was cited as being of great importance by over $65 \%$ of the respondents. Over $23 \%$ of the respondents also indicated that the price of food is of some importance. 


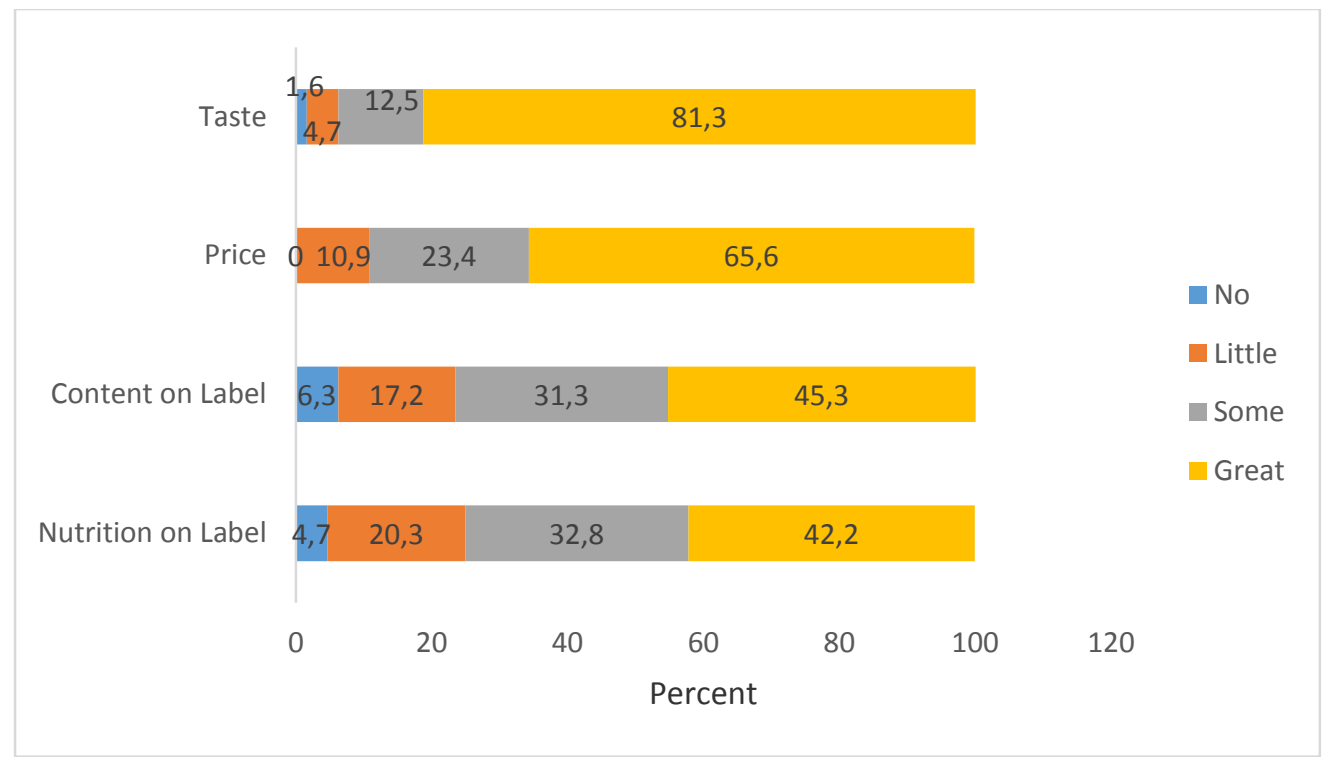

Figure 3: Importance of Food Attributes

\section{Willingness to Pay More for Food Attributes}

Respondents were willing to pay more for food based on where and how it was produced. Over $82 \%$ of the respondents either strongly agreed $(51.3 \%)$ or agreed $(30.8 \%)$ that they will be willing to pay more for food that is produced locally. Food produced on small farms ranked second in terms of willingness to pay more. Over $46 \%$ of the respondents strongly agreed that they were willing to pay more for food produced on small farms and another $30.8 \%$ agreed with the statement. Food produced organically was a close third based on willingness to pay more, with $41 \%$ and $35.9 \%$ of the respondents strongly agreeing and agreeing, respectively, that they will be willing to pay more for such food. A majority of the respondents (69.3\%) also either strongly agreed or agreed that they will be willing to pay more for food processed in extra safe conditions. 


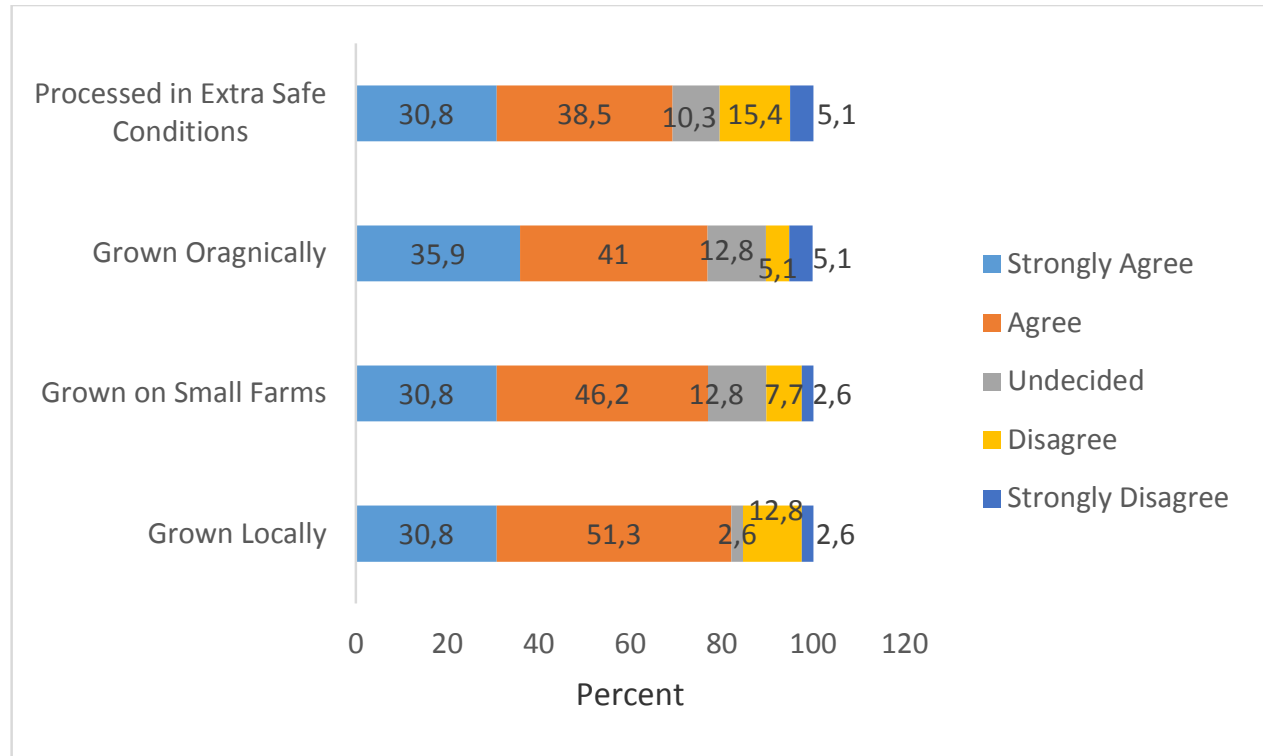

Figure 4: Wiilingness to Pay More for Food Based Production Practices

\section{Conclusion}

The majority of students in this study got their FAH from supermarkets and FAFH from fast food restaurants on a weekly basis. The most important food attributes were taste and price. Food vendors that could provide goodtasting food at lower prices are likely to have a competitive edge in attracting students as patrons. Students also indicated a strong willingness to pay more for locally-produced food. The interest of younger people in local foods indicate that the local food movement could be sustained for a longer period.

\section{References:}

1. Anderson, D. A., Shapiro, J. R., \& Lundgren, J. D. (2003). The freshman year of college as a critical period for weight gain: An initial evaluation. Eating Behaviors, 4, 363-367.

2. Baker, S. (1991). College cuisine makes mother cringe. American Demographics, 13(9), 10-13.

3. Betts, N. M., Amos, R. J., Georgiou, C., Hoerr, S. L., Ivaturi, R., Keim, K. S., \& Voichick, J. (1995). What young adults say about factors affecting their food intake a. Ecology of Food and Nutrition, 34(1), 5964.

4. Birch, L. L. (1999). Development of food preferences. Annual review of nutrition, 19(1), 41-62. 
5. Bissonnette, M. M., \& Contento, I. R. (2001). Adolescents' perspectives and food choice behaviors in terms of the environmental impacts of food production practices: application of a psychosocial model. Journal of nutrition education, 33(2), 72-82.

6. Brevard, P. B., \& Ricketts, C. D. (1996). Residence of college students affects dietary intake, physical activity, and serum lipid levels. Journal of the American Dietetic Association, 96(1), 35-38.

7. Centers for Disease Control. (1997). Youth risk behavior surveillance: National college health risk behavior survey - United States. Mortality and Morbidity Weekly Report, 46(SS-6), 1-54.

8. Deshpande, S., Basil, M. D., \& Basil, D. Z. (2009). Factors influencing healthy eating habits among college students: An application of the health belief model. Health marketing quarterly, 26(2), 145-164.

9. Driskell, J. A., Kim, Y.-N., \& Goebel, K. J. (2005). Few differences found in the typical eating and physical activity habits of lower-level and upper-level university students. Journal of the American Dietetic Association, 105, 798-801.

10. Glanz, K., Basil, M., Maibach, E., Goldberg, J., \& Snyder, D. A. N. (1998). Why Americans eat what they do: taste, nutrition, cost, convenience, and weight control concerns as influences on food consumption. Journal of the American Dietetic Association, 98(10), 1118-1126.

11. Glanz, K., \& Eriksen, M. P. (1993). Individual and community models for dietary behavior change. Journal of Nutrition Education, 25(2), 80-86.

12. Glanz, K., Lewis, F. M., \& Rimer, B. K. (1997). The scope of health promotion and health education. Health behavior and health education. San Francisco: Jossey-Bass, 318.

13. Grace, T. W. (1997). Health problems of college students. Journal of American College Health, 45, 243-250.

14. Marquis, M. (2005). Exploring convenience orientation as a food motivation for college students living in residence halls. International Journal of Consumer Studies, 29, 55-63.

15. Nguyen, M. N., Otis, J., \& Potvin, L. (1996). Determinants of intention to adopt a low-fat diet in men 30 to 60 years old: implications for heart health promotion. American Journal of Health Promotion, 10(3), 201207.

16. Nicklas, T. A., Baranowski, T., Baranowski, J. C., Cullen, C., Rittenberry, L., \& Olvera, N. (2001). Family and child-care provider influences on preschool children's fruit, juice, and vegetable consumption. Nutrition Reviews, 59, 224-235. 
17. Racette, S. B., Deusinger, S. S., Strube, M. J., Highstein, G. R., \& Deusinger, R. H. (2005). Weight changes, exercise, and dietary patterns during freshman and sophomore years of college. Journal of American College Health, 53, 245-251.

18. Rappoport, L. (2003). How we eat. Appetite, culture, and the psychology of food. Toronto, Canada: ECW Press.

19. Sporny, L. A., \& Contento, I. R. (1995). Stages of change in dietary fat reduction: social psychological correlates. Journal of Nutrition Education,27(4), 191-199.

20. Wimberly, R. C., Vander May, B. J., Wells, B. L. and Ejimakor G. C. 2003. The Globalization of Food and How Americans Feel About It. Southern Perspective, 6(2), Southern Rural Development Center. 